\title{
MEDIDAS SOCIOEDUCATIVAS DE PRESTAÇÃO DE SERVIÇOS À COMUNIDADE E DE LIBERDADE ASSISTIDA EM FOZ DO IGUAÇU - BRASIL
}

\author{
Murilo Schurt Alves ${ }^{1}$ \\ Denise Rissato²
}

Marcos Augusto Moraes Arcoverde ${ }^{3}$

Para citar este artículo puede utilizar el siguiente formato:

Murilo Schurt Alves, Denise Rissato y Marcos Augusto Moraes Arcoverde: "Medidas socioeducativas de prestação de serviços à comunidade e de liberdade assistida em foz do Iguaçu - Brasil", Revista Caribeña de Ciencias Sociales (vol 10, № 7 julio-septiembre 2021, pp. 38-50. En línea:

https://www.eumed.net/es/revistas/caribena/julio-septiembre-2021/prestacao-servicos

\section{RESUMO}

O objetivo deste trabalho é apresentar dados de realização das medidas socioeducativas de prestação de serviço à comunidade (PSC) e de liberdade assistida (LA), em Foz do Iguaçu, no período de 2015 a 2018, bem como, traçar o perfil dos adolescentes que cumpriram as referidas medidas. Para atender aos objetivos propostos, foi realizada uma pesquisa bibliográfica, documental e entrevistas com profissionais que acompanharam os adolescentes em cumprimento das medidas socioeducativas supracitadas. Constatou-se que foram acompanhados 751 adolescentes pelas equipes multiprofissionais de socioeducadores. Observou-se que esses adolescentes, em sua maioria, eram do sexo masculino, tinham entre 15 e 17 anos de idade, não haviam concluído o ensino fundamental, não trabalhavam ou atuavam em atividades informais e haviam cometido infrações de tráfico, furto ou assalto. Em média, 14,64\% desses adolescentes reincidiram em algum ato infracional. Essas características evidenciam que, a despeito da proposta inovadora do Estatuto da Criança e do Adolescente, a socioeducação enquanto política pública, ainda se destina majoritariamente aos adolescentes pobres. Por fim, pode-se afirmar que a apesar das dificuldades e limitações materiais, humanas e institucionais enfrentadas no processo de realização do trabalho socioeducativo em Foz do Iguaçu no período estudado, ocorreram avanços quantitativos e

\footnotetext{
1 Acadêmico do 3 o ano do curso de Direito da Universidade Estadual do Oeste do Paraná - UNIOESTE, Campus de Foz do Iguaçu. Bolsista PIBIC/Fundação Araucária.

2 Doutora em Políticas Públicas e Formacão Humana pela Universidade do Estado do Rio de Janeiro - PPFH/UERJ; Professora Efetiva da Universidade Estadual do Oeste do Paraná - UNIOESTE - Campus de Foz do Iguaçu; Pesquisadora do GPESTE - Grupo de Pesquisa em Estado, Sociedade, Trabalho e Educação. Pesquisadora e Líder do Grupo de Pesquisa em Estado, Políticas Públicas e Cidadania - GPEPPC.

3 Doutor em Enfermagem em Saúde Pública pela Universidade de São Paulo, Ribeirão Preto. Professor Efetivo da Universidade Estadual do Oeste do Paraná - UNIOESTE - Campus de Foz do Iguaçu; Pesquisador do Grupo de Pesquisa em Estado, Políticas Públicas e Cidadania - GPEPPC. Docente do Programa de Pós-Graduação em Saúde Pública em Região de Fronteira. ID Orcid: https://orcid.org/0000-0001-5104-559X
} 
qualitativos que imprimiram um novo ritmo de realização desta política pública, sobretudo a partir de 2016, após a contratação de novas equipes multiprofissionais que passaram a atuar no Centro de Referência Especializada de Assistência Social (CREAS).

Palavras-chave: Adolescentes; Ato Infracional; Medida Socioeducativa; Política Pública; Proteção Social.

\title{
CORRECTIONAL MEASURES FOR COMMUNITY SERVICE AND ASSISTED FREEDOM IN FOZ DO IGUAÇU - BRAZIL
}

\begin{abstract}
This work is based on a bibliography, documents and interviews with professionals who accompanied teenagers in compliance with the socio-educational measures of community service (PSC) and assisted freedom (LA), in Foz do Iguaçu, in 2015. In 2018, we sought to present data on the performance of such measures and to trace the profile of adolescents who complied with these socioeducational measures of that period. It was found that 751 adolescents were followed by the multiprofessional teams of socio-educators. Most of these adolescents were found to be male, between 15 and 17 years old, having not completed elementary school, having not worked or worked in informal activities, and had committed trafficking, theft or assault charges. On average, $14.64 \%$ of these adolescents relapsed in some offense. These characteristics show that, despite the innovative proposal of the Statute of Children and Adolescents, social education as a public policy is still mainly aimed at poor adolescents. Finally, it can be stated that despite the material, human and institutional difficulties and limitations faced in the process of carrying out socio-educational work in Foz do Iguaçu during the study period, there were quantitative and qualitative advances that gave a new rhythm to the realization of this public policy, especially from 2016, after hiring new multiprofessional teams that started to work at the Specialized Reference Center for Social Assistance (CREAS).
\end{abstract}

Descriptors: Adolescent; Infraction; Correctional Measures; Public Policy; Social Protection.

\section{MEDIDAS SOCIOEDUCATIVAS PARA EL SERVICIO COMUNITARIO Y LA LIBERTAD ASISTIDA EN FOZ DE IGUAÇU - BRASIL}

\section{RESUMEN}

En este trabajo, basado en una bibliografía, documental y entrevistas con profesionales que acompañaron a adolescentes en cumplimiento de las medidas socioeducativas de servicio comunitario (PSC) y libertad asistida (LA), en Foz do Iguaçu, en el periodo de 2015 a 2018, buscamos presentar datos sobre el desempeño de tales medidas y rastrear el perfil de los adolescentes que cumplieron con estas medidas socioeducativas en ese período. Se constató que 751 adolescentes fueron acompañados por los equipos multiprofesionales de socio educadores. Se 
observó que la mayoría de estos adolescentes eran del sexo masculino, tenían entre 15 y 17 años, no habían completado la escuela primaria, no trabajaban ni actuaban en actividades informales y habían cometido tráfico, robo o asalto. En promedio, el $14.64 \%$ de estos adolescentes repitieron algún delito. Estas características muestran que, a pesar de la propuesta innovadora del Estatuto de Niños y Adolescentes, la educación social como política pública sigue dirigida principalmente a los adolescentes pobres. Finalmente, se puede afirmar que a pesar de las dificultades y limitaciones materiales, humanas e institucionales enfrentadas en el proceso de realización del trabajo socioeducativo en Foz do Iguaçu durante el período de estudio, hubo avances cuantitativos y cualitativos que dieron un nuevo ritmo a la realización de esta política pública, especialmente a partir de 2016, después de contratar nuevos equipos multiprofesionales que comenzaron a trabajar en el Centro de Referencia Especializado para Asistencia Social (CREAS).

Descriptores: Adolescente; Infracción; Medida Socioeducativa; Política Pública Protección Social.

\section{INTRODUÇÃO}

No contexto da redemocratização brasileira e da consolidação dos direitos humanos e sociais recém instituídos pela Constituição Federal de 1988, após longas disputas políticas e profícuos debates com a participação de diversos setores da sociedade civil engajados na luta em favor dos direitos das crianças e dos adolescentes, foi promulgada a Lei Federal ํㅜ 8.069, de 13 de julho de 1990, também conhecida como Estatuto da Criança e do Adolescente (ECA), que busca superar as legislações e as políticas meramente assistencialistas, até então implementadas no Brasil.

Dentre os mais importantes avanços trazidos pelo ECA, pode-se destacar a definição das diretrizes orientadoras da ação estatal no caso de crianças e adolescentes que praticam ato infracional, com o intuito de garantir-lhes proteção integral, respeitando sua condição peculiar de desenvolvimento (Rizzini; Rizzini, 2004).

Cabe ressaltar que a legislação brasileira voltada para a infância e adolescência, anterior ao ECA, fundamentava-se na doutrina penal do menor, preconizada pelo Código Penal do Império (1830) e no princípio da situação irregular, inaugurado pela Lei no 6.697/79, também conhecida como Segundo Código de Menores (Pereira, 2008) que, segundo Rizzini (2000), institucionalizou um modelo assistencialista de controle e punição, fortalecendo os estigmas e a criminalização das crianças e adolescentes que viviam privadas de proteção, cuidados e direitos básicos.

De acordo com o ECA, os adolescentes menores de 18 anos de idade, em conflito com a lei, são penalmente inimputáveis, mas devem ser acompanhados, assistidos e tutelados pelo Estado por meio de seis medidas socioeducativas (advertência, obrigação de reparar o dano causado, prestação de serviços à comunidade, à liberdade assistida, semiliberdade e internamento) cuja aplicação pode variar dependendo da gravidade da infração cometida e/ou da reincidência infracional (Lei oㅜ 8.069, de 13 julho de 1990). Essas medidas podem ser divididas em dois grupos: aquelas cumpridas sem privação de liberdade, executadas em meio aberto (obrigação de reparar o dano, prestação de 
serviço à comunidade e liberdade assistida) e aquelas cumpridas em regime semiaberto (semiliberdade) ou regime fechado (internação).

Todavia, apesar dos avanços trazidos pelo ECA, depois de quase três décadas da sua aprovação, ainda existem a socioeducação no Brasil é capaz de revelar inúmeras dificuldades ainda enfrentadas em sua operacionalização que acabam por impor limites ao seu alcance pedagógico e ressocializador (Liberati, 2006; Bandeira, 2006; Morais et al, 2018).

Diante disso, pretende-se conhecer a realidade da socioeducação em Foz do Iguaçu, um município inserido na tríplice fronteira Argentina-Brasil-Paraguai que, além de compartilhar todos os problemas socioeconômicos relativos ao capitalismo dependente latino-americano, também precisa enfrentar as particularidades e singularidades que o tornam um território único.

Portanto, este trabalho tem como objetivo descrever e discutir o perfil dos adolescentes que cumpriram as medidas socioeducativas de prestação de serviço à comunidade (PSC) e de liberdade assistida (LA), bem como, os dados de realização de tais medidas em Foz do Iguaçu, no período de 2015 a 2018, com base em dados e informações coletadas por meio de uma pesquisa bibliográfica, documental e de entrevistas com profissionais que acompanham adolescentes em cumprimento das referidas medidas socioeducativas no Centro de Referência Especializado de Assistência Social (CREAS) no município.

Cabe destacar que essa pesquisa foi aprovada pelo Comitê de Ética em Pesquisa envolvendo Seres Humanos da Universidade Estadual do Oeste do Paraná.

\section{1. $O$ adolescente em conflito com a lei e a socioeducação em regime aberto}

Nessa seção, realizou-se uma breve discussão das diretrizes gerais das medidas socioeducativas de prestação de serviços à comunidade e de liberdade assistida.

A prestação de serviços à comunidade está regulamentada no artigo 117 do ECA e consiste na realização de tarefas gratuitas de interesse geral, por período máximo de seis meses, junto a entidades assistenciais, hospitais, escolas e outros estabelecimentos congêneres, além de programas comunitários e governamentais. Conforme o artigo 90 , inciso $\mathrm{V}$ da referida lei, as entidades supracitadas, são responsáveis pela elaboração e execução da medida socioeducativa de prestação de serviços à comunidade, estabelecendo deveres e metas de cunho pedagógico ao adolescente. Ademais, o adolescente, que irá cumprir tal medida, somente deverá ser incumbido de tarefas que não prejudiquem sua escolarização e/ou sua jornada de trabalho e que estimulem o desenvolvimento de suas potencialidades, respeitando o princípio da dignidade da pessoa humana e o caráter pedagógico que deve permear a socioeducação (Lei ํㅡ‥069, de 13 julho de 1990).

De acordo com Digiácomo e Digiácomo (2017, p. 205), as disposições acima mencionadas visam coibir que os adolescentes em conflito com a lei sejam incumbidos de serviços inadequados, degradantes e/ou de caráter meramente punitivo, ou ainda que executem a medida socioeducativa em entidades despreparadas, com profissionais que os recebam com hostilidade e discriminação. Os autores ainda destacam que o nome da medida fala por si, "[...] o serviço deve ser prestado 'à comunidade', e não 'à entidade', sob pena de caracterização de 'exploração do trabalho' do 
adolescente". Portanto, faz-se necessário não apenas um projeto adequado que descreva as atividades que serão desempenhadas, mas também a sua fiscalização, de modo a constatar e prevenir possíveis abusos praticados.

Para Bandeira (2006), a medida socioeducativa de prestação de serviços à comunidade está fortemente pautada pela intervenção mínima do Estado na esfera íntima do adolescente que cometeu ato infracional, buscando evitar o seu encarceramento e, por conseguinte, a supressão de sua individualidade. Essa medida socioeducativa, portanto, deve criar as condições para que ele reflita sobre as consequências do ato infracional na esfera social, orientando-o para o pleno exercício de sua cidadania.

A liberdade assistida, por sua vez, está regulamentada nos artigos 118 e 119 do ECA (Lei no 8.069, de 13 julho de 1990). Para Liberati (2006), apesar do texto legal não trazer um conceito jurídico da referida medida, a mesma pode ser definida como um programa de atendimento de cunho eminentemente pedagógico, oferecido pelo Poder Público ou entidade não-governamental, a ser cumprido pelo adolescente em meio aberto, com o objetivo de reorganizar sua vida na família, na escola e na comunidade.

Nesse sentido, Bandeira (2006) acrescenta que a medida socioeducativa de liberdade assistida deve ser aplicada por uma entidade que tenha estrutura física e humana capaz de auxiliar e fortalecer os laços de afetividade entre o adolescente e a família, orientando-o e inserindo-o em programas de auxílio, supervisionando a frequência e o aproveitamento escolar.

Não se trata de uma mera "liberdade vigiada", na qual o adolescente estaria em uma espécie de "período de prova", mas sim importa em uma intervenção efetiva e positiva na vida do adolescente e, se necessário, em sua dinâmica familiar, por intermédio de uma pessoa capacitada para acompanhar a execução da medida, chamada de "orientador", que tem a incumbência de desenvolver uma série de tarefas, expressamente previstas no art. 119, do ECA (Digiácomo; Digiácomo, p. 206, 2017).

Cabe destacar ainda que, segundo o artigo 52 da Lei oㅜ 12.594/2012 que institui o Sistema Nacional de Atendimento Socioeducativo (Sinase), o cumprimento de qualquer medida dependerá de instrumento de previsão, registro e gestão das atividades a serem desenvolvidas com o adolescente, denominado Plano Individual de Atendimento - PIA (Lei no 12.594, de 18 de janeiro de 2012).

Segundo Bandeira (2006), o PIA é elaborado a partir de um estudo de caso, onde são registrados dados e informações do adolescente e dos seus representantes legais para entender as circunstâncias que o levaram à prática de ato infracional, bem como, as atividades socioeducativas a serem cumpridas por ele, sob a orientação e o acompanhamento profissional e institucional, com o intuito de ajudá-lo a superar suas dificuldades e identificar novas perspectivas para a sua vida.

Isso posto, salienta-se que para que as medidas socioeducativas consigam produzir os efeitos desejados, é imprescindível a atuação intersetorial de diversos órgãos, agindo de maneira conjunta e articulada na vida desses adolescentes. Como explica Digiácomo (2018), esse sistema de organização e operacionalização foi denominada como "rede de proteção"4 pela Lei № 13.431 de 4 de abril de 2017, que estabelece o sistema de garantia de direitos infanto-juvenis.

\footnotetext{
${ }^{4}$ Conforme seu artigo 14, "as políticas implementadas nos sistemas de justiça, segurança pública, assistência social, educação e saúde deverão adotar ações articuladas, coordenadas e efetivas voltadas ao acolhimento e ao atendimento
} 


\section{Dados de realização das medidas socioeducativas de prestação de serviços à comunidade e de liberdade assistida em Foz do Iguaçu no período de 2015 a 2018}

Nesta seção serão apresentados e discutidos dados referentes ao número de adolescentes que cumpriram as medidas socioeducativas de PSC e de LA no CREAS, ao número de atendimentos realizados pelos profissionais das equipes especializadas, bem como, a proporção de adolescentes atendidos que reincidiram em cada ano do período analisado. Essas informações foram fornecidas pela Secretaria Municipal de Assistência Social de Foz do Iguaçu e estão apresentadas, a seguir, nas tabelas 1,2 e 3.

\section{Tabela 1 -}

Número total de adolescentes acompanhados pelo CREAS no cumprimento de medidas socioeducativas de PSC e LA em Foz do Iguaçu, no período de 2015-2018.

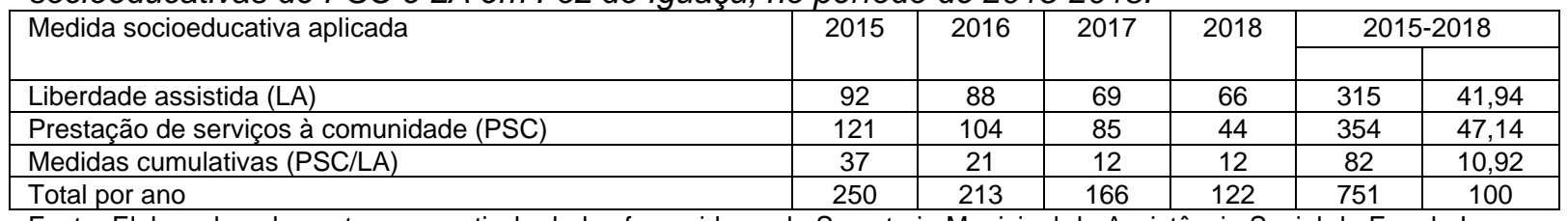

Fonte: Elaborada pelos autores a partir de dados fornecidos pela Secretaria Municipal de Assistência Social de Foz do Iguaçu $-\mathrm{PR}$.

Conforme a Tabela 1, é possível constatar que 751 adolescentes foram assistidos pela equipe multidisciplinar do CREAS para cumprimento de medidas socioeducativas de PSC e/ou de LA no período de 2015-2018. Dentre esse número, 10,92\% dos adolescentes cumpriram as medidas cumulativamente, situação prevista nos artigos 99 e 113 do ECA. Ainda, verifica-se que ocorreu uma queda de $48,8 \%$ no número total de adolescentes que cumpriram as medidas supracitadas, de forma isolada ou cumulativa, entre 2015 e 2018.

No que diz respeito à redução gradativa do número de adolescentes atendidos anualmente no período de 2015-2018, cabe observar que esses dados, por si só, não permitem tirar conclusões definitivas, sendo necessária uma análise sobre o cumprimento de outras medidas socioeducativas para verificar se também ocorreu uma redução ou apenas uma transferência de adolescentes das medidas aqui estudadas para outras modalidades.

Acrescenta-se que em 2015, a Vara da Infância e da Juventude de Foz do Iguaçu, concedeu medida liminar para que a Administração Municipal realizasse, no prazo de 180 dias, concurso público para contratação de assistentes sociais, psicólogos e educadores para atuarem nos CRAS e CREAS do município. A decisão, atendeu à ação civil pública ajuizada pela $15^{\underline{a}}$ Promotoria de Justiça da comarca que denunciava a insuficiência de profissionais e de estrutura física para atender a população infanto-juvenil em situação de vulnerabilidade (Jusbrasil, 2019). Com isso, foi possível atender os adolescentes que aguardavam atendimento socioeducativo nessas instituições, o que explica tanto o elevado número de adolescentes que cumpriram medidas socioeducativas no CREAS

integral às vítimas de violência" (Lei № 13.431 de 4 de abril de 2017). Digiácomo (2018) cita como membros da "rede de proteção": Conselho Municipal dos Direitos da Criança e do Adolescente, Conselho Tutelar, Juiz da Infância e da Juventude, Promotor da Infância e da Juventude, professores e diretores de escolas, responsáveis pelas entidades não-governamentais de atendimento a crianças, adolescentes e famílias, dentre outros. 
em 2015 e 2016 (Tabela 1), quanto o significativo aumento do número total de atendimentos dos profissionais do serviço social e da psicologia, a partir de 2016 (Tabela 2).

Tabela 2 -

Atendimentos da equipe multidisciplinar aos adolescentes em conflito com a lei em cumprimento de medidas socioeducativas de PSC e LA e de suas respectivas famílias em Foz do Iguaçu, no período 2015-2018.

\begin{tabular}{|l|l|l|l|}
\hline Atendimento por cada categoria profissional & 2015 & 2016 & 2017 \\
\hline Psicologia & 212 & 681 & 898 \\
\hline Educador & 2.986 & 2.549 & 2.039 \\
\hline Serviço Social & 265 & 783 & 1.722 \\
\hline Equipe AFAI $^{1}$ & n.d. $^{3}$ & 340 & 670 \\
\hline Equipe PAEFI $^{2}$ & n.d. $^{3}$ & n.d. $^{3}$ & 144 \\
\hline
\end{tabular}

Fonte: Elaborada pelos autores a partir de dados fornecidos pela Secretaria Municipal de Assistência Social de Foz do Iguaçu - PR.

Legenda: (1) Atuam na Atenção às Famílias dos Adolescentes Internados por medida socioeducativa. (2) Atuam no Serviço de Proteção e Atendimento Especializado a Famílias e Indivíduos em situação de vulnerabilidade. (3) Dados não disponíveis.

Outro dado relevante sobre a realização das medidas socioeducativas de PSC e LA é o número de adolescentes reincidentes que cumpriram as referidas medidas no período estudado.

Tabela 3 -

Proporção anual de adolescentes reincidentes que cumpriram medidas socioeducativas de PSC e LA em Foz do Iguaçu, no período 2015-2018.

\begin{tabular}{|c|c|c|c|}
\hline Ano & Adolescentes em medidas socioeducativas & Total de reincidentes & Proporção (\%) \\
\hline 2015 & 250 & 22 & 8,8 \\
\hline 2016 & $\mathbf{2 1 3}$ & $\mathbf{n}$.d. & n.d. \\
\hline 2017 & 166 & 27 & 16,27 \\
\hline 2018 & 122 & 23 & 18,85 \\
\hline
\end{tabular}

Fonte: Elaborada pelos autores a partir de dados fornecidos pela Secretaria Municipal de Assistência Social de Foz do Iguaçu - PR.

Legenda: (1) Dados não disponíveis.

Conforme a Tabela 3, nota-se que, em termos absolutos, o número de reincidentes que cumpriram as medidas socioeducativas de PSC e de LA, no período analisado, variou entre 22 e 27 adolescentes. Observa-se ainda, que mesmo com o decréscimo do número de adolescentes que cumpriram medidas socioeducativas, em termos absolutos, o número de reincidentes permaneceu praticamente constante o que explica o aumento da proporção dos adolescentes reincidentes no período estudado. Cabe ressaltar que, nesse caso, qualquer análise baseada apenas na proporção de adolescentes reincidentes poderia levar a conclusões equivocadas a respeito do trabalho socioeducativo realizado pelos profissionais, reiterando os argumentos daqueles que não acreditam no alcance social e na eficácia da política socioeducativa e corroborando com os discursos em defesa da redução maioridade penal.

\section{Perfil socioeconômico dos adolescentes que cumpriram medidas socioeducativas de prestação de serviços à comunidade e/ou de liberdade assistida em Foz do Iguaçu, no período de 2015 a 2018.}

Com base nos dados mostrados na Tabela 4, verifica-se que dentre os adolescentes que cumpriram as medidas de PSC e/ou de LA no período estudado, em média, $81,67 \%$ eram do sexo 
masculino. Observa-se ainda que, em média $72,64 \%$ desses adolescentes, independentemente do sexo, tinham entre 15 e 17 anos de idade.

No que diz respeito à escolarização dos referidos adolescentes, constatou-se que, aproximadamente, $81,29 \%$ deles ainda não havia completado o ensino fundamental (primeiro ao nono ano), na ocasião em que cumpriram as medidas socioeducativas de PSC e/ou LA. Considerando que, aproximadamente, $40 \%$ dos adolescentes tinham 17 anos de idade ou mais e, portanto, poderiam estar cursando o ensino médio, percebe-se a grande maioria desses adolescentes se encontravam em situação de defasagem escolar, frequentando séries escolares incompatíveis com a sua idade cronológica, por reprovação e/ou abandono escolar.

Dentre as causas do elevado índice de abandono e reprovação escolar, pode-se mencionar a desigualdade e a vulnerabilidade social enfrentada pela grande maioria das famílias desses adolescentes, situação que os obriga a ingressar precocemente no mercado de trabalho, muitas vezes, informal, precário e, até mesmo ilícito, para ajudar no sustento familiar.

Com relação à ocupação laboral desses adolescentes, verifica-se que, em média, 21,9\% deles trabalhavam regularmente no mercado informal, enquanto apenas $7,31 \%$ trabalhavam com carteira assinada. Analisando os dados anuais, observa-se que ao mesmo tempo em que ocorreu uma redução contínua, ano após ano, do percentual de adolescentes que trabalhavam com registro em carteira de trabalho, passando de 11,6\% em 2015 para apenas 4,1\% em 2018, houve um aumento percentual daqueles que trabalhavam regularmente no mercado informal, passando de $16,8 \%$ para $27,05 \%$ nos respectivos anos.

\section{Tabela 4 -}

Caracterização do perfil socioeconômico dos adolescentes em conflito com a lei em cumprimento de medidas socioeducativas de PSC e LA, Foz do Iguaçu, 2015 - 2018 (em \%).

\begin{tabular}{|c|c|c|c|c|c|}
\hline Variáveis & 2015 & 2016 & 2017 & 2018 & Média do período \\
\hline \multicolumn{6}{|l|}{- Sexo } \\
\hline Masculino & 76,4 & 84,04 & 77,71 & 88,52 & 81,67 \\
\hline Feminino & 23,6 & 15,96 & 22,29 & 11,48 & 18,33 \\
\hline \multicolumn{6}{|l|}{ - Idade } \\
\hline 12 a 14 anos & 16,4 & 12,21 & 21,08 & 19,68 & 17,34 \\
\hline 15 anos & 20 & 19,72 & 19,28 & 15,57 & 18,64 \\
\hline 16 anos & 24 & 26,29 & 21,69 & 22,95 & 23,73 \\
\hline 17 anos & 26,4 & 32,39 & 29,52 & 32,79 & 30,27 \\
\hline 18 anos acima & 12,8 & 8,92 & 8,43 & 9,02 & 9,79 \\
\hline Não Informado & 0,4 & 0,47 & 0 & 0 & 0,22 \\
\hline \multicolumn{6}{|l|}{ - Escolarização } \\
\hline Ensino fundamental incompleto ( $1^{a}-9^{a}$ série) & 76,4 & 82,16 & 81,32 & 85,25 & 81,29 \\
\hline Ensino médio incompleto & 22,4 & 17,84 & 18,07 & 12,3 & 17,65 \\
\hline Ensino médio completo & 1,2 & 0 & 0,6 & 0,82 & 0,66 \\
\hline Não informada & 0 & 0 & 0 & 1,64 & 0,41 \\
\hline \multicolumn{6}{|l|}{ - Ocupação } \\
\hline Não trabalha & 70 & 66,2 & 76,51 & 68,85 & 70,39 \\
\hline Trabalha com registro & 11,6 & 7,51 & 6,02 & 4,1 & 7,31 \\
\hline Trabalha sem registro & 16,8 & 26,29 & 17,47 & 27,05 & 21,9 \\
\hline Estagiário & 1,2 & 0 & 0 & 0 & 0,3 \\
\hline Não Informada & 0,4 & 0 & 0 & 0 & 0,1 \\
\hline \multicolumn{6}{|l|}{ - Ato infracional cometido } \\
\hline Tráfico & 32 & 32,39 & 29,52 & 33,06 & 31,74 \\
\hline Furto ou assalto & 26 & 32,39 & 33,13 & 22,88 & 28,6 \\
\hline Lesão corporal ou agressão & 11,6 & 5,64 & 11,45 & 3,23 & 7,98 \\
\hline Porte ilegal de arma & 7,2 & 2,35 & 7,83 & 9,68 & 6,76 \\
\hline Outros $^{(1)}$ & 23,2 & 27,25 & 18,05 & 25,8 & 23,6 \\
\hline
\end{tabular}

Fonte: Elaborada pelos autores a partir de dados fornecidos pela Secretaria Municipal de Assistência Social de Foz do Iguaçu $-\mathrm{PR}$. 
Legenda: (1) Atos infracionais como receptação, abuso sexual, ameaça, crime de trânsito, calúnia, falso crime, difamação, injúria, posso de entorpecentes, vandalismo, kit cadeia, bullying, tentativa de homicídio, homicídio, latrocínio, extorsão, desacato, contrabando, descaminho e estelionato tiveram menos de $4 \%$ cada e entraram nesta categoria.

Ainda, cabe ressaltar que, de acordo com os dados da SMAS/CREAS, $70,39 \%$ dos adolescentes não estavam trabalhando, pelo menos não regularmente, durante o período em que estiveram cumprindo medidas socioeducativas de PSC e/ou de LA. No entanto, parece oportuno destacar que, muitas vezes, esses adolescentes são recrutados para realizar trabalhos informais e, até mesmo, ilícitos em situações eventuais, sentindo-se constrangidos em declarar informações mais detalhadas a respeito, ou simplesmente deixando de informá-las quando não foram realizadas regularmente. Essa pesquisa apontou que um dos maiores desafios que se coloca à socioeducação em Foz do Iguaçu é garantir oportunidades de formação e trabalho.

Com o objetivo de inserir o adolescente em conflito com a lei no mercado de trabalho, o SMAS/CREAS mantém parceria constante e prioritária com a Guarda Mirim de Foz do Iguaçu (GMFI), associação com fins não econômicos e de assistência social que busca promover a formação técnica-profissional de adolescentes através do Programa de Aprendizagem, conforme as diretrizes da Lei Federal oㅜ 10.097/00 (Lei o 10.097 de 19 de dezembro de 2000). Além disso, a GMFI oferece, além do seu programa comum de aprendizagem ${ }^{5}$, atividades complementares como serviços de auxílio escolar e oficina de música, atendimento psicossocial, palestras, práticas que incentivam o esporte, a leitura e o lazer, entre outras atividades formativas com a finalidade tanto de potencializar suas habilidades para o mercado de trabalho, na condição de aprendiz, quanto de promover o pleno exercício de sua cidadania (Guarda Mirim de Foz do Iguaçu, 2019).

Entretanto, segundo relatos dos profissionais que acompanham o cumprimento das medidas socioeducativas no CREAS, uma das grandes dificuldades enfrentadas pela GMFI é conseguir ocupação laboral para os adolescentes do sexo masculino com dezessete anos ou mais $(30,37 \%)$, pois no ano em que completam 18 anos de idade devem apresentar-se ao serviço militar. Nas palavras de um profissional entrevistado, "os meninos - muitos deles - que chegam aos 17 anos, a Guarda Mirim não consegue encaminhar porque as empresas que contratam têm a questão do alistamento militar. Se o menino se alista e é chamado, tem que romper o contrato" (Profissionais entrevistados).

Além disso, para aqueles que não estão na faixa etária de 17 anos, ainda há uma grande dificuldade para se conseguir uma vaga na Guarda Mirim, isto porque há uma desproporção entre a oferta de trabalho e a demanda de interessados. Um dos entrevistados da equipe multidisciplinar do CREAS indaga: "a Guarda Mirim tem uma fila de cinco mil na lista de espera, como dar conta de toda essa questão do trabalho?" (Profissionais entrevistados).

Ainda, segundo os profissionais do CREAS, na tentativa de superar esse obstáculo, esses adolescentes são encaminhados para cursos profissionalizantes e os seus currículos são enviados para empresas locais, embora muitos não sejam contratados pela baixa escolaridade.

\footnotetext{
${ }^{5}$ Com a demanda de aprendizes do mercado de trabalho, o departamento de Serviço Social realiza visitas domiciliares e entrevistas sociais para os adolescentes ingressarem na Guarda Mirim. Após esta primeira seleção, são encaminhados para as entrevistas. Quando há aprovação de 30 adolescentes, inicia-se uma turma de aprendizagem, com atividades teóricas na GMFI e práticas no estabelecimento contratante. O tempo total de contrato equivale a 16 meses para a carga horária de 20 horas semanais, conforme as diretrizes do Ministério do Trabalho (Guarda Mirim de Foz do Iguaçu, 2019).
} 
Em decorrência disso, no mercado formal, restam poucas alternativas de ocupação para esses adolescentes que, em geral, são empregados em serviços braçais que, na maioria das vezes, dificultam a sua permanência na escola, conforme argumenta o profissional entrevistado na fala destacada a seguir.

E aí qual é o trabalho formal que sobra para eles? Construção civil, que é pesado... aí não vão para a escola, porque ou você trabalha ou você estuda, e não é fácil trabalhar o dia inteiro numa construção civil e ir para a escola à noite (Profissionais entrevistados)

Nota-se, portanto, que o profissional entrevistado salienta a importância do trabalho, desde que o direito à educação e a escolarização sejam garantidos e tratados como prioridade pelo Estado e pela sociedade civil, pois são condição primordial para que outras oportunidades possam surgir na vida desses adolescentes. Inclusive porque, segundo Jacobina e Costa (2007), os adolescentes têm dificuldades, em nossa sociedade mercantilizada, para escolher entre os ganhos imediatos do trabalho, ainda que precário e mal pago, e os possíveis benefícios, no longo prazo, de uma maior escolarização e/ou qualificação profissional.

Além disso, a percepção individual do trabalho pelo adolescente deveria basear-se "no fato de a pessoa gostar do que faz, no reconhecimento de que a atividade traz desafios que a faz aprender novos conhecimentos e desenvolver seu potencial" (Jacobina; Costa, 2007, p. 106). No entanto, os resultados dessa pesquisa apontam que em decorrência da falta de oportunidades de trabalho formal para os adolescentes em conflito com a lei, dificilmente as vagas de trabalho oferecidas contemplam suas aspirações pessoais de qualificação profissional, representando, muitas vezes, apenas uma punição ou, quando muito, uma possibilidade de ajudar financeiramente a sua família e de suprir suas necessidades básicas de subsistência.

De acordo com as informações obtidas pelo CREAS, verificou-se que a maioria dos adolescentes eram provenientes de famílias pobres que enfrentavam dificuldades para garantir sua subsistência, vivendo em arranjos familiares predominantemente monoparentais ou estendidos em famílias compostas por quatro ou mais pessoas, com uma renda de até dois salários mínimos. Isso mostra que a necessidade de contribuir para a subsistência familiar é determinante na hora desses adolescentes escolherem dentre as poucas oportunidades de ocupação laboral e de escolarização que se Ihes apresentam. Isto posto, Rissato (2015) enfatiza que a falta de oportunidades de profissionalização e de ocupação laboral decente, em geral, expõem esses adolescentes a situações de risco e vulnerabilidade que, muitas vezes, representam a porta de entrada para o ato infracional. $O$ depoimento de um profissional entrevistado reitera esse entendimento:

A questão da renda familiar é precária e não consegue subsidiar a alimentação. Eles recorrem ao ato infracional para trazerem sustento para dentro de casa. [...] às vezes o que a Guarda Mirim oferece em um mês, $\mathrm{R} \$ 500,00$, eles conseguem tirar, no tráfico, em um dia. [...] o que faz os meninos irem para o infracional é a desigualdade, o que faz eles voltarem é a desigualdade (Profissionais entrevistados).

Essa realidade fica ainda mais evidente quando são analisados os dados sobre os atos infracionais cometidos pelos adolescentes em questão, evidenciando que o tráfico $(31,74 \%)$ e 0 furto/assalto $(28,6 \%)$ foram as principais infrações cometidas no período estudado (Tabela 4$)$. 
Por fim, essa pesquisa vem mostrando que o senso comum, o preconceito e os estigmas presentes no discurso e na prática cotidiana, inclusive em instituições da rede de proteção, tem imposto sérios desafios à socioeducação, enquanto política pública de proteção social, em Foz do Iguaçu. As entrevistas trouxeram alguns relatos que evidenciam essa questão, conforme a fala a seguir.

O trabalho socioeducativo [...] possibilita que a gente veja esses meninos, o que de fato, muitas vezes não acontece. Em muitos espaços só reforçam o estigma do "adolescente infrator", ou do "menor", do "marginal". [...] até parece mentira, mas há escolas que colocam em seus relatórios que os adolescentes que cumprem medidas são "sementinhas do mal". [...] É bem difícil, ele não é visto com bons olhos, ele não é visto como um adolescente, ele é visto como um bandido (Profissionais entrevistados).

Muitas vezes, os próprios profissionais que trabalham nas instituições que compõe a rede protetiva, reproduzem e legitimam esses estigmas, ainda que inconscientemente. Nesse sentido, um dos entrevistados mencionou o discurso de um conselheiro tutelar durante uma conferência sobre direitos infanto-juvenis, que ao ser indagado sobre a falta de vagas de trabalho para adolescentes em conflito com a lei, respondeu: "se os bons têm que esperar, porque os ruins não podem?" (Profissionais entrevistados).

\section{CONSIDERAÇÕES FINAIS}

Verificou-se que as medidas estudadas, a despeito das dificuldades enfrentadas em decorrência dos investimentos insuficientes do município, assumiram um novo ritmo de realização, a partir de 2016, após a contratação de novas equipes multiprofissionais que passaram a atuar no CREAS. Isso não apenas garantiu que todos os adolescentes encaminhados para cumprir as referidas medidas pudessem ser assistidos, mas também permitiu um aumento significativo desses atendimentos tanto para os adolescentes quanto para os seus familiares.

Além disso, constatou-se que, os 751 adolescentes que cumpriram as referidas medidas no período, em sua maioria, eram do sexo masculino, tinham entre 15 e 17 anos de idade, não haviam concluído o ensino fundamental, atuavam em atividades informais ou não trabalhavam, eram provenientes de famílias pobres e haviam cometido infrações de tráfico, furto ou assalto, sendo que, em média, $14,64 \%$ deles reincidiram em algum ato infracional.

Para finalizar, essa pesquisa mostrou que o senso comum, o preconceito e os estigmas, lamentavelmente, ainda estão presentes no discurso e na prática da sociedade, constituindo-se em um dos principais obstáculos enfrentados pelos adolescentes, suas famílias e pelos profissionais do CREAS que buscam garantir seus direitos.

\section{REFERÊNCIAS}

Bandeira, Marcos Antonio S. (2006). Atos infracionais e medidas socioeducativas: uma leitura dogmática, crítica e constitucional. Ilhéus: Editus. 
Lei ํㅜ 8.069, de 13 julho de 1990. Dispõe sobre o Estatuto da Criança e do Adolescente e dá outras providências. Diário Oficial [da] República Federativa do Brasil, Brasília, DF, 16 jul. 1990. Disponível em: <http://www.planalto.gov.br/ccivil_03/leis/l8069.htm>. Acesso em: 15 ago. 2019.

Lei ํo 10.097 de 19 de dezembro de 2000. Altera dispositivos da Consolidação das Leis do Trabalho - CLT, aprovada pelo Decreto-Lei ํㅜ 5.452 de 1ํ de maio de 1943. Diário Oficial [da] República Federativa do Brasil, Brasília, DF, 20 dez. 2000. [Acessado em 04 de novembro de 2019]. Disponível em: Disponível em:<http://www.planalto.gov.br/ccivil_03/leis/l10097.htm>.

Lei oㅜ 12.594, de 18 de janeiro de 2012. Institui o Sistema Nacional de Atendimento Socioeducativo SINASE. Diário Oficial [da] República Federativa do Brasil, Brasília, DF, 19 jan. 2012. [Acessado em 30 de julho de 2019]. Disponível http://www.planalto.gov.br/ccivil_03/_Ato2011-2014/2012/Lei/L12594.htm>.

Lei $n=13.431$ de 4 de abril de 2017. Estabelece o sistema de garantia de direitos da criança e do adolescente vítima ou testemunha de violência. Diário Oficial [da] República Federativa do Brasil, Brasília, DF, 05 abr. 2017. [Acessado em 15 de agosto de 2019]. http://www.planalto.gov.br/ccivil_03/_Ato2015-2018/2017/Lei/L13431.htm>.

Sistema Nacional de Atendimento Socioeducativo - SINASE. Brasília: CONANDA, 2006.

Digiácomo, Murillo J. \& Digiácomo, Ildeara A. (2017). Estatuto da criança e do adolescente anotado e interpretado. Curitiba: Ministério Público do Estado do Paraná.

Digiácomo, Murillo J. (2019). O desafio do trabalho em "rede". [Acessado em 20 de agosto de 2019]. http://www.crianca.mppr.mp.br/modules/conteudo/conteudo.php?conteudo=390 > .

Guarda Mirim de Foz do Iguaçu. (2019). Projeto pedagógico. [Acessado em 15 de agosto de 2019]. Disponível em: <http://guardamirimfoz.org.br/down/Projeto_Pedag\%C3\%B3gicoSocial_GMFI.pdf>.

Jacobina, O. M. P. \& Costa, L.F. (2007). "Para não ser bandido": Trabalho e adolescentes em conflito com a lei. Cadernos de Psicologia social do trabalho, v. 10, n. 2, p. 95-110.

Jusbrasil. (2019). Município deve promover concurso público para contratação de funcionários para CRAS e CREAS. [Acessado em 15 de setembro de 2019]. Disponível em: <https://mppr.jusbrasil.com.br/noticias/160198331/13-01-foz-do-iguacu-municipio-deve-promoverconcurso-publico-para-contratacao-de-funcionarios-para-cras-e-creas $>$.

Liberati, Wilson. D. (2006). Execução das medidas em meio aberto - prestação de serviços à comunidade e liberdade assistida. In: ILANUD, Justiça, adolescente e ato infracional: socioeducação e responsabilização. São Paulo, ILANUD, p. 367-396.

Morais, Juscislayne Bianca T. et al. (2018). Medidas Socioeducativas: A Intervenção Estatal na Expressão da Questão Social da Violência Praticada por Adolescentes. Sociedade em Debate, v. 24, n. 3, p. 79-96.

Pereira, Tânia da S. (2008). Direito da Criança e do Adolescente: uma proposta interdisciplinar. 2. ed. Rio de Janeiro: Renovar. 
Rissato, D. (2015). Políticas sociais, pobreza e risco infanto-juvenil no contexto de realização do Programa Bolsa Família em Foz do Iguaçu - Paraná. Tese Doutoral orientada por Eveline Algebaile. Rio de Janeiro: Universidade do Estado do Rio de Janeiro, 293 p.

Rizzini, Irene (2000). A Criança e a Lei no Brasil - Revisitando a História (1822-2000). Brasília, DF: NICEF; Rio de Janeiro: USU Ed. Universitária, p. 28.

Rizzini, Irene \& Rizzini, Irma (2004). A institucionalização de crianças no Brasil: percurso histórico e desafios do presente. São Paulo: Edições Loyola. 